\title{
Process of surface micro melting and polishing on 3Cr2Mo steel with scanning electron beam and its effect on the microstructure and proper- ties of hardening layer
}

\author{
R. Wang \&J.W. Yin \&D.Q .Wei \\ College of mechanical and electrical, Guilin University of Electronic technology, Guilin, Guangxi, \\ China \\ Email:jingwei8872@126.com
}

KEYWORD: 3Cr2Mo steel; scanning electron beam; micro melting and polishing; roughness; metallurgical structure; hardness

\begin{abstract}
Process of surface micro melting and polishing can reduce surface roughness so as to improve the surface mechanical properties. Process of surface micro melting and polishing on 3Cr2Mo steel is re-searched in this paper and the microstructure and properties of surface hardening layer are analyzed. The re-sults show that surface roughness is reduced by $41.1 \%$ and surface average hardness is $724 \mathrm{HV}$ after the sample whose surface roughness is $1.472 \mu \mathrm{m}$ is processed by surface micro melting and polishing. The cross-section microstructure is composed of hardened zone, transition zone and matrix. The distribution of cross-section morphology of hardened zone is like "W"; The microstructures of hardened zone are composed of acicular martensite and lath martensite; The microstructures of transition zone are composed of cryptocrystalline martensite, residual austenite, troostite and tempered sorbite; The deepest hardened zone reaches about $520 \mu \mathrm{m}$; The change of microhardness $(650 \mathrm{HV} 715 \mathrm{HV})$ is not obvious which is 2.26 2.4 times as hard as matrix.
\end{abstract}

\section{INTRODUCTION}

With growth of people's demand on the industrial products, demand on surface quality of products is more and more high and improving surface polishing technology and shortening product cycle have been problems that should be solved. Electron beam polishing technology is studied as a new type of polishing technology. Electron beam polishing belongs to non-contact polishing method and it has advantages of high energy utilization ratio, realizing automation control easily and nonpollution and so on (Tan, 2013 \&Chen, 2009). At present, different electron beam polishing methods have been chosen to be studied by scholars at home and abroad. The research (Gao, 2009 \& Gao, 2010) shows that pulsed electron beam has obvious polishing effect on titanium alloy and pulse energy has obvious influence on surface polishing result; (Okada, 2008 \& Murray, 2013) Adopt the method of large area irradiation with electron beam and surfaces of operation tools and fixtures are polished. Defocused electron beam is used to melt or evaporate metal surface rapidly so as to polish surface efficiently. (Uno. et al. 1989) Adopt plasma electron beam(PBEB) in which the maximum diameter is $60 \mathrm{~mm}$ to irradiate surface of smooth die steel workpiece. After irradiation, roughness of the processed surface is reduced and corrosion resistance is improved.

In this paper, scanning electron beam polishing method is used to melt and polish the surface of 3Cr2Mo steel; Effect of micro melting and polishing on surface roughness and microstructures and properties of the hardened layer of section is discussed.

\section{TEST EQUIPMENT AND MATERIALS}

\subsection{Test material}

Experimental materials selected 3Cr2Mo plastic die steel, its chemical composition (in wt.\%) is: $\mathrm{C}, 0.28 \sim 0.4 ; \mathrm{Si}, 0.2 \sim 0.8 ; \mathrm{Mn}, 0.6 \sim 1.0 ; \mathrm{P}, \leq 0.03 ; \mathrm{S}, \leq 0.03 ; \mathrm{Cr}, 1.4 \sim 2.0 ; \mathrm{Mo}, 0.3 \sim 0.55$. The sample test, with a vertical milling machine processed into $40 \times 40 \times 40 \mathrm{~mm}^{3}$, and are divided into groups and numbered. 


\subsection{Electron beam scanning way}

The way by using scanning electron beam microfusion polished on surface of 3Cr2Mo steel is shown in Figure 1. During the test, the same amplitude of sine wave and cosine wave signal is input along the direction of $x$ and $y$ sepectively. Under the effect of magnetic field, high-speed electron generates corresponding deflection in the Oxy plane. High-speed electron synthetics ring-type heat source in the Oxy plane. Through debugging electron beam equipment and testing measurement, scanning radius of electron beam is controlled to $4 \mathrm{~mm}$. Fixing the position of scanning electron beam bottom and according to the set speed, the sample surface micro melting polishing effect is achieved by moving the stage. Based on the research results of other people (Chen. et al. 2012), scan process parameters are set as follows: accelerating voltage $60 \mathrm{kV}$; electron beam $25 \mathrm{~mA}$; worktable movement speed $3 \mathrm{~mm} / \mathrm{s}$; scanning radius $4 \mathrm{~mm}$; focusing current $380 \mathrm{~mA}$ and scanning frequency $300 \mathrm{~Hz}$.

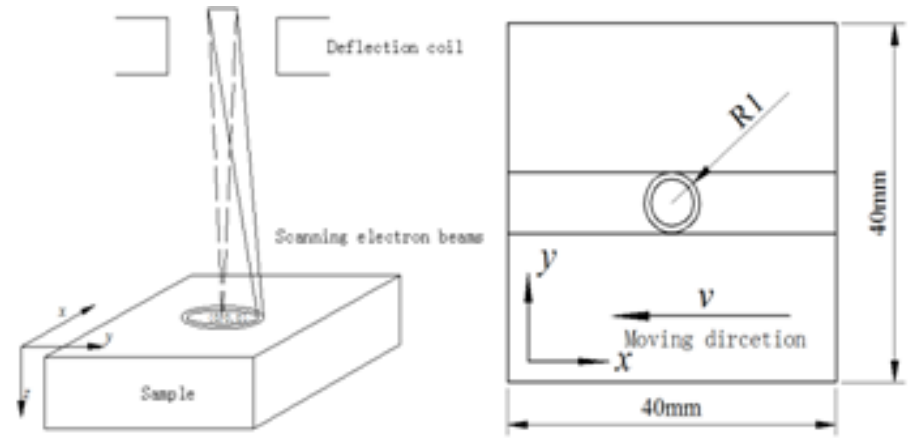

Figure 1. Scanning electron beam

\section{EXPERIMENTAL RESULTS AND ANALYSIS}

\subsection{Surface roughness}

Surface morphology obtained after microfusion polishied by electron beam scanning on surface of milling sample is shown in Figure 2. The original machining surface scratches visible and surface changes significantly which can be seen from Figure 2 (a). The surface roughness is measured as: $\mathrm{Ra}=1.472 \mu \mathrm{m}$. Surface through a scanning electron beam microfusion polished treatment is shown in Figure 2 (b). On the surface, its mechanical scratch ablates and dimple decreased obviously, it tends to be flat. Surface roughness: $\mathrm{Ra}=0.867 \mu \mathrm{m}$, the results show that surface roughness is reduced by $41.1 \%$. Surface polishing effect is improved obviously. This is because electron beam scanning acting on the material surface. The surface layer absorbs energy. The instantaneous energy density reaches a certain threshold and forms of great heat effect zone formation temperature gradient. The surface temperature reaches the melting point peak instantaneous projection ablation. Due to gravity and different radius of curvature, the molten metal flows towards big radius of curvature. When the sample matrix transfer heat cooling fastly, the melting liquid metal cools solidification rapidly and ultimately the polishing effect of surface finishs. 


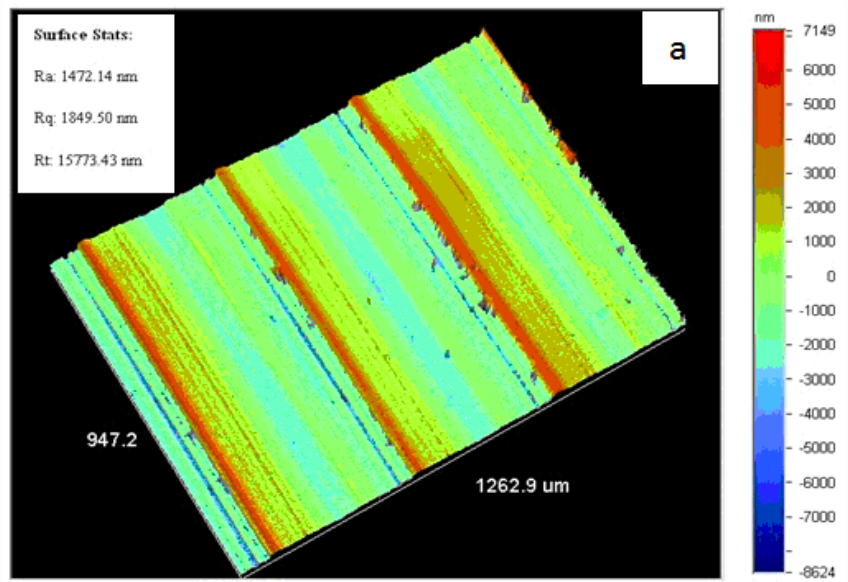

(a) Machined surfaces

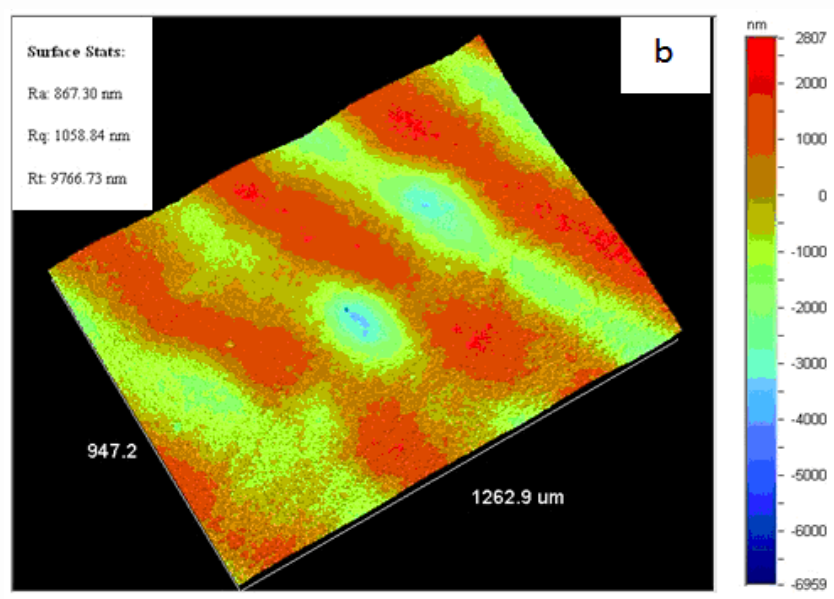

(b) Micro-polished surface after melting

Figure 2. 3D surface topography

\subsection{Hardening layer microstructure analysis}

The surface of sample after scanning electron beam microfusion polished cuts along the direction perpendicular by wire cutting machine. The cross-section of cut specimen grinds and polishes. Alcohol it with $4 \%$ nitric acid corrosion. The Scanning electron microscopy is selected by taking organize photographs. Organize get-section is shown in Figure 3.

From Figure 3 (a), after scanning electron beam melting surface microfusion polished, 3Cr2Mo divides into hardened steel structure, transition zone and the substrate. Hardened layer is obtained like shape of "W". Circular heat source scans each point in the process of equal energy density. As is shown in Figure 1 (a), when it moves along $\mathrm{x}$ axis direction with table, the points along the $\mathrm{y}$ axis diameter circular heat source by annular heat source two different intervals superimposed heat. Energy accumulation is also different. Center of energy density accumulation time interval is long. Energy density accumulation is less. Energy density near the edge of the accumulation time interval is short. Energy density of accumulated is more. This results in hardened layer presenting like "W" distribution.

Seen from Figure 3 (b), cross section appears about $520 \mu \mathrm{m}$ hardened layer by scanning electron processed for treatment. Hardened zone group is acicular martensite and board strips martensite. Temperature rises sharply by electron beam rapid heating. The organization austenitizing, scanning electron beam is in a short time to stay above the phase transition temperature. It is too late to grow rapidly in the austenite cooled to form acicular and lath martensite. Figure 3 (c) is the transition zone. When the scanning electron beam is heating in this area, temperature is between Ac1 Ac3. As temperature distribution in the depth direction is uneven, cooling rate results to be inconsistent. After the final cooling, microstructure is coexistence phenomenon of implicit needle martensite, re- 
sidual austenite troostite and tempered sorbite. Seen from Figure 3 (d), the original sample is tempered sorbite tissue.

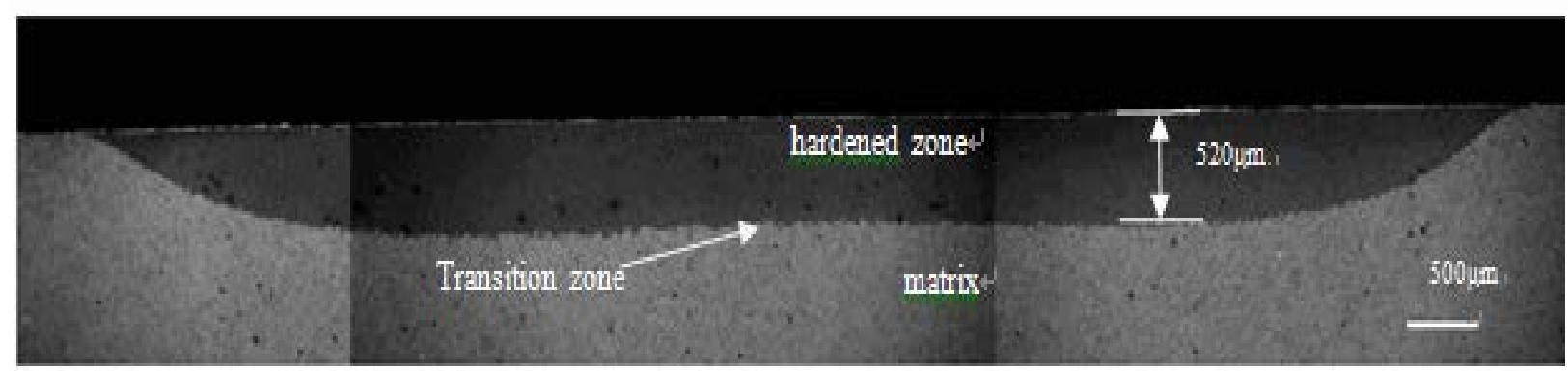

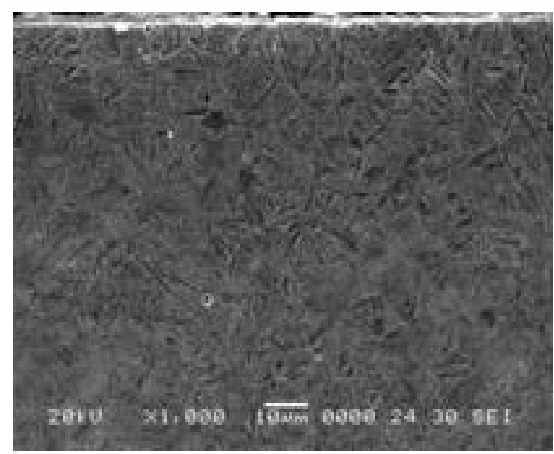

(b) Hardening zone organization
(a)Hardening zone panorama

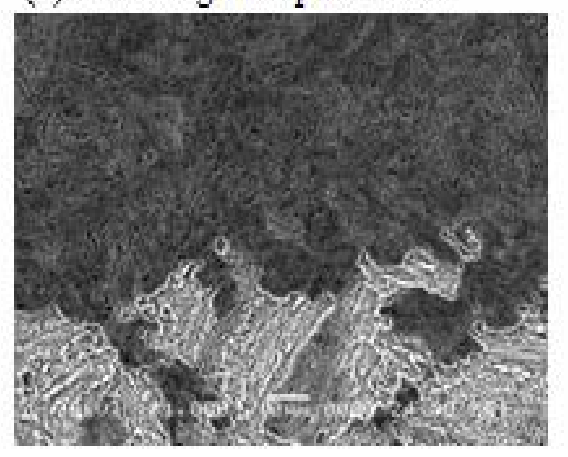

(c) Transition zone organization

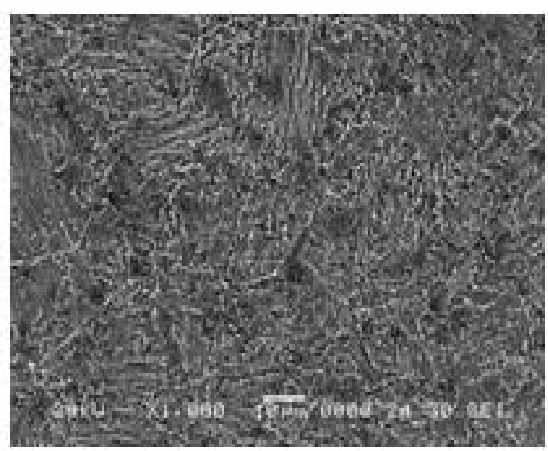

(d) Matrix organization

Figure 3. 3Cr2Mo Microfused polished steel hardened zone microstructure

\subsection{Copying old text onto new file}

Seen from Figure 4(a), 3Cr2Mo average hardness of the steel substrate is 298HV. After using scanning electron beam microfusion polished, surface average hardness value is 724HV. Polishing surface hardness value is about 2.43 times than that of hardness of matrix. Seen from Figure 4(b), microhardness test is done from the depth direction of hardened zone sectional. After microfusion polished, the deepest of microfusion hardening zone is about $520 \mu \mathrm{m}$. Hardening zone microhardness value is $650 \mathrm{HV} 715 \mathrm{HV}$. It is 2.26 to 2.4 times than substrate. This is because when using scanning electron beam microfusion polished, sample surface occurs micron grade melting crest. The characteristics of electron beam is rapid heating and rapid cooling. Hardened zone achieves quenching effect. Hardness decreasing appears in transition zone of organization diversity. Hardness at the base remaines stable. 


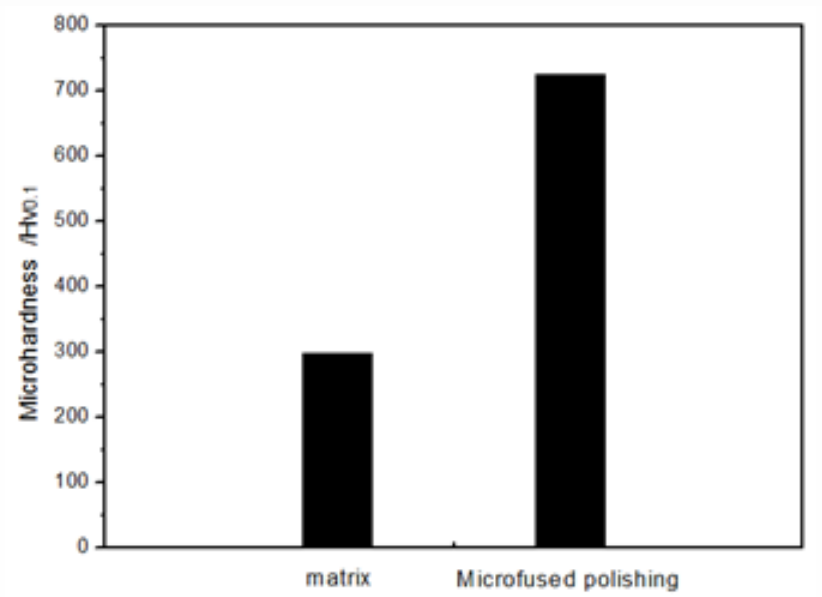

(a) Matrix and Microfused polished surface hardness

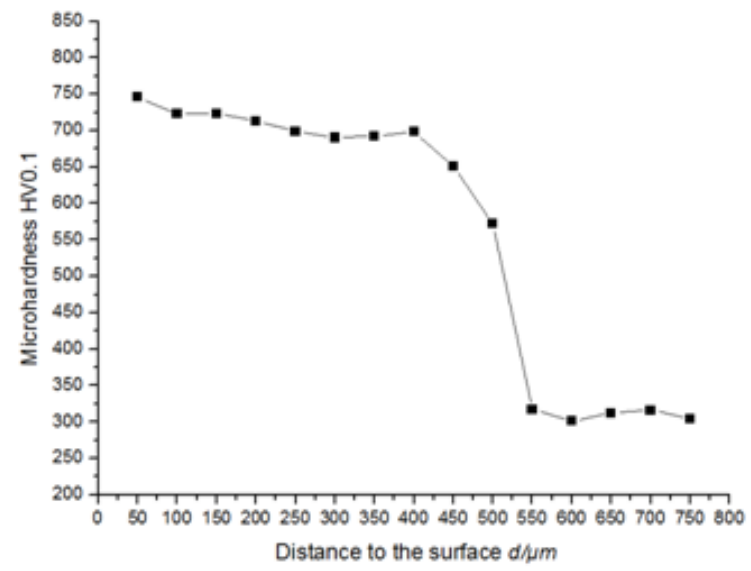

(b) Sectional hardness distribution in the depth direction

Fig.4 Hardness Testing

\section{CONCLUSION}

(1) By using scanning electron beam microfusion polished on surface of 3Cr2Mo steel, surface roughness reduction is $41.1 \%$. Surface hardness value is about $724 \mathrm{HV}$ and it is 2.43 times than that of matrix.

(2) After using scanning electron beam microfusion polished, cross section is divided into hardened zone, transition zone and matrix. Hardened zone group is acicular martensite and board strips martensite. Transition zone is composed by implicit needle martensite, residual austenite of sorbite, troostite and tempering.

(3) After using scanning electron beam microfusion polished, cross-section microhardness hardening area $(650 \mathrm{HV} 715 \mathrm{HV})$ changes small and it is 2.26 2.4 times than that of matrix.

\section{ACKNOWLEDGEMENTS}

This work was financially supported by the guangxi Natural Science Funded Project (2012GXNSFDA053026).

\section{References}

[1] Okada, Y.Uno, et al. Surface finishing of stainless steels for orthopedic surgical tools by largearea electron beam irradiation [J]. Manufacturing Technology, 2008, 57:223-226.

[2] Chen. H.C, wei.D.Q, wang.R. numerical simulation of temperature field of in electron beam surface hardening process on 45 steel[J]. Journal of materials, heat treatment, 2012, 8:161-166. 
[3] J.W.Murray, P.K.Kinnell, ea al. Surface finishing of intricate metal mould structures by largearea electron beam irradiation [J]. Precision Engineering ,2013,37:443-450.

[4] Y. Tan, S. Shi. Progress in research and development of electron beam technology in metallurgy refining field[J]. Journal of materials engineering, 2013 (8): 92-92.

[5] Y.F. Chen, X. Yang. Electron beam engineering technology and application [J], 2009 (8): 153153.

[6] Y.K. Gao, F. Liu, Q. Wang. Influence of Pulsed electron beam polishing modification of TC21 titanium alloy [J]. Metal heat treatment, 2009 (5): 38-40.

[7] Y.K.Gao. Microstructure and property of TC4 titanium alloy by pulsed electron beam modification [J]. Journal of materials, heat treatment, 2010, 31 (4): 120-124.

[8] Y.Uno, A.Okada, K.Uemura,et al. A new polishing method of metal mold with Large-area electron beam irradiation[J]. Journal of Materials Processing Technology,2007,187-188:77-80. 